\title{
高速切り替え分析技術
}

\author{
渡辺淳* \\ 株式会社島津製作所 \\ （2016年7月 5 日受理）
}

\section{Triple quadrupole mass spectrometer and its speed performance}

\author{
Jun Watanabe \\ Shimadzu Corporation, 1, Nishinokyo Kuwabara-cho, Nakagyo-ku, Kyoto 604-8511, Japan
}

Keywords: LC-MS/MS, triple quadrupole, MRM, UHPLC, multi-residue pesticide analysis, polarity switching.

\section{は じめに}

各種研究開発や試験検查などの業務において, LC-MS/ MSが広く使用されている，LC-MS/MSを用いることで，超 多成分の一斉検出が可能であるため, 1 度の分析で多くの化 合物に対するスクリーニング分析を行うことができる。ま た，ターゲット化合物の選択性が向上するため, HPLCでの 分離を質量分析に担わせることで，HPLCの分析時間をより 短くすることが可能であり, さらにいわゆるサブ $2 \mu \mathrm{m}$ の粒 子系カラムで超高速分析をすることができる.

本稿では, 残留農薬分析において幅広く活用されているト リプル四重極型質量分析計を用いた高速分析にあたり，必要 となる技術を紹介する.

\section{1. 感度}

食品中の残留農薬のスクリーニング分析を行うにおいて重 要なのは, 対象成分が基準值以上入っているかの判別であ る.したがって, 定量分析における正確さ, 基準值が分析で きる高感度，が必要な要件となる，LC-MSにはいろいろな

\footnotetext{
* = 604-8511 京都市中京区西ノ京桑原町 1

E-mail: jun_wtnb@shimadzu.co.jp

(c) 日本農薬学会
}

種類の原理を用いた質量分析計があり，それぞれ分析の得手 不得手がある。ここでは詳細は省くが, 定量分析に一番有用 な質量分析計は四重極型の質量分析計であり（表1), さら にトリプル四重極型質量分析計により感度・選択性を向上さ せることができる。

トリプル四重極型質量分析計はいくつかのベンダーから上 市されており，各ベンダーともに複数の装置ラインナップを 上市している．多くは感度仕様が異なるものである．質量分 析計のラインナップ間での感度比較の一例を図 1 に示した。 残留農薬の分析において必要となるのは, 上述のとおり対象

表 1. 質量分析計の特徵. 四重極型質量分析計が定量分析には一 番適している

\begin{tabular}{|c|c|c|c|c|c|c|}
\hline & 測定範囲 & $\begin{array}{l}\text { 取扱い } \\
\text { やすさ }\end{array}$ & $\begin{array}{l}\text { 精密質 } \\
\text { 量測定 }\end{array}$ & $\begin{array}{l}\mathrm{MS}^{n} \\
\text { 測定 }\end{array}$ & 定性 & 定量 \\
\hline 四重極型QP & $\begin{array}{l}\sim m / z \\
2000\end{array}$ & (a) & $\times$ & $x$ & $\triangle$ & (C) \\
\hline $\begin{array}{c}\text { イオントラッ } \\
\text { プ型IT }\end{array}$ & $\begin{array}{l}\sim m / z \\
2000\end{array}$ & 0 & $x$ & 0 & () & $\times$ \\
\hline $\begin{array}{c}\text { 飛行時間型 } \\
\text { TOF }\end{array}$ & $\begin{array}{l}\text { 理論的に } \\
\text { 無制限 }\end{array}$ & 0 & 0 & $x$ & () & $\triangle$ \\
\hline 磁場型 Sector & $\begin{array}{l}\sim m / z \\
10000\end{array}$ & $x$ & 0 & $\times$ & () & $\bigcirc$ \\
\hline
\end{tabular}



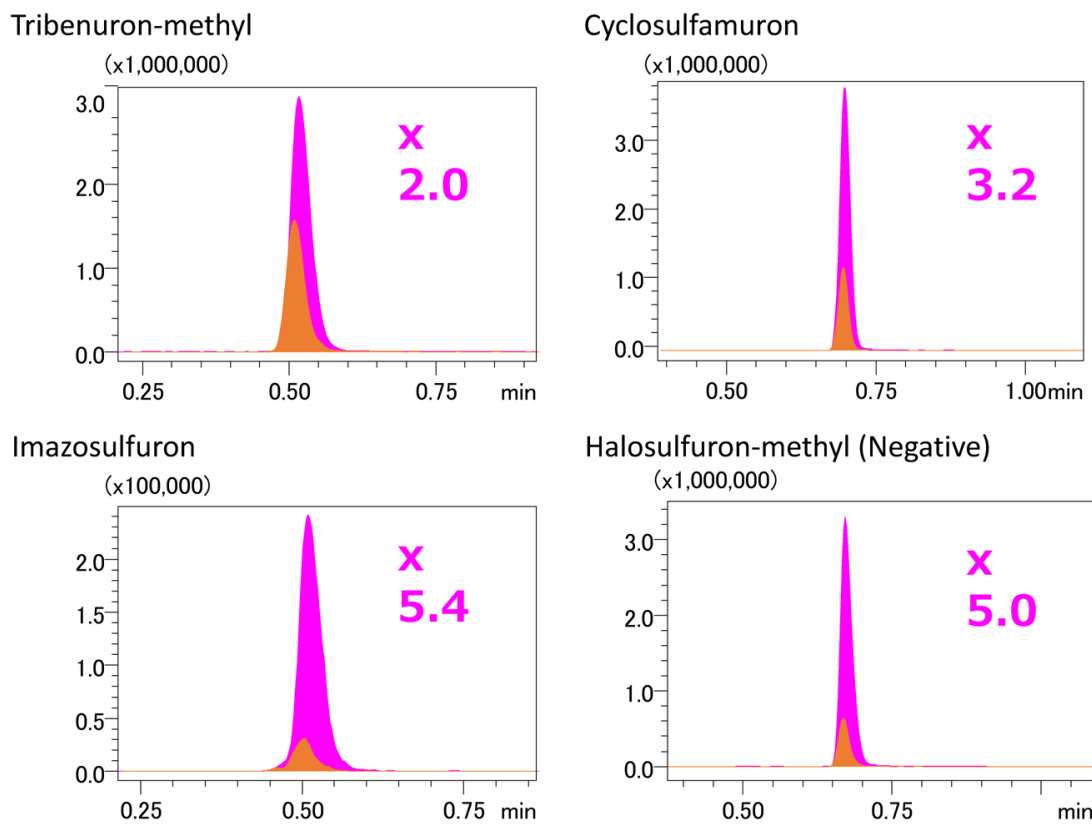

Halosulfuron-methyl (Negative)

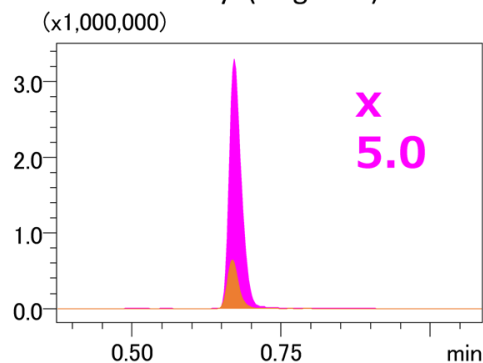

LCMS-8030 と

LCMS-8040では、

種々の化合物で

2-5倍程度の感度

の差がある。

図 1. 複数装置間での感度比較. 島津製作所製トリプル四重極型質量分析計LCMS-8030（赤）と LCMS-8040（桃）の比較データ.

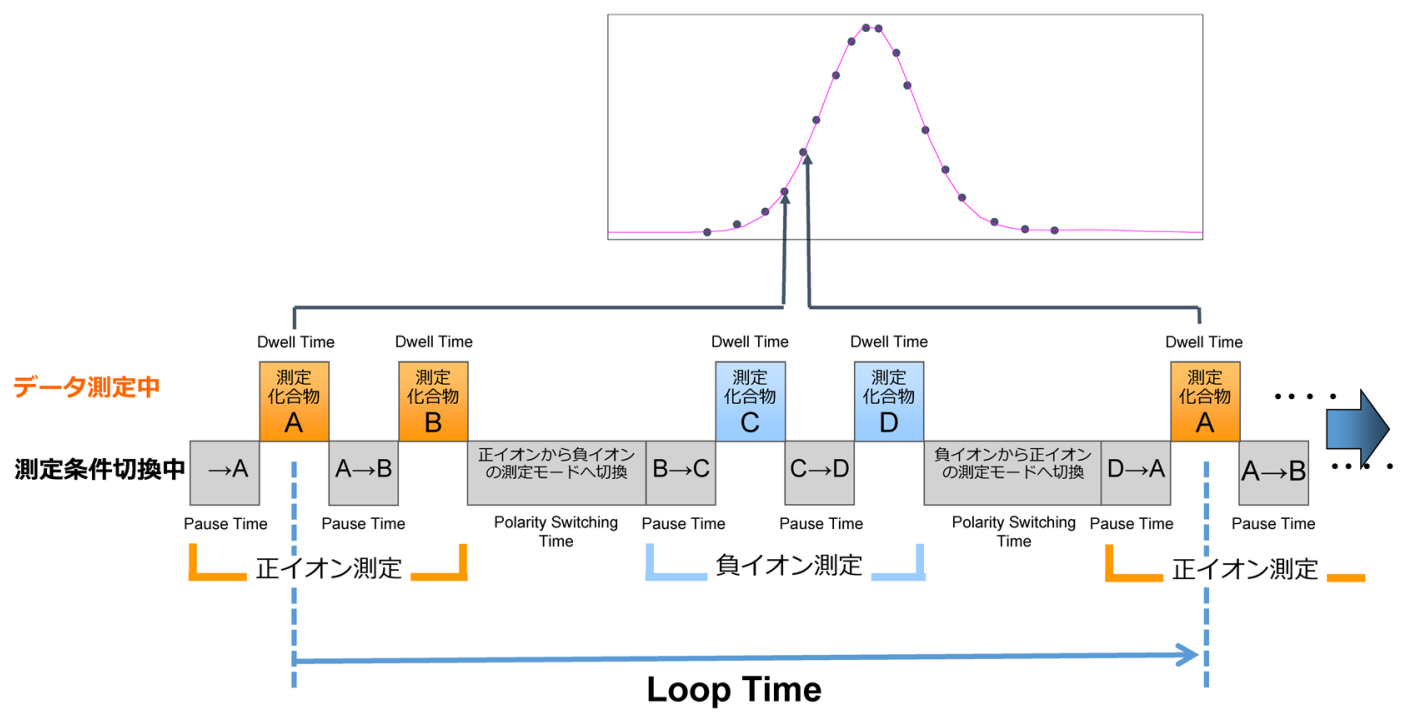

図2. 四重極型質量分析計での測定４４種類の化合物をポジネガ切り替えしながら測定する場合の MRM測定の設定．Loopが繰り返される ことで分析が行われる.

成分の基準值付近を分析できるかどうかであり，とりわけ， 一律基準值の $10 \mathrm{ppb} そ$ や $1 / 10,1 / 100$ の濃度まで分析でき ることが要求される。

\section{2. 高速イオン搬送}

トリプル四重極型質量分析計では, 複数の化合物を一斉に 分析するために，非常に短い時間の中で複数の化合物それぞ れの分析を繰り返し行う。ターゲットの化合物を分析して いる時間を dwell time, 化合物から次の化合物に切り替える ための時間を pause time, 対象化合物の極性が切り替わると
きに必要な時間を正負イオン化切り替え時間，と呼び，それ ぞれを設定したメソッドを用いて分析を行う（図2）。Loop timeはクロマトのピーク幅に依存するが，通常，1秒程度に 設定する。したがって，ターゲットの化合物数が少ない場 合, dwell timeを比較的長い時間（たとえば $100 \mathrm{msec}$ な゙） に設定することができるが, 残留農薬スクリーニングでは ターゲット化合物数が多いため, dwell timeを $5 \mathrm{msec} な と ゙$ 短 い時間に設定する必要がある. Pause timeによる切り替え 後, ターゲット化合物の dwell timeが始まっても, イオン化 部と検出器に距離があるため, イオンは即座には検出器には 


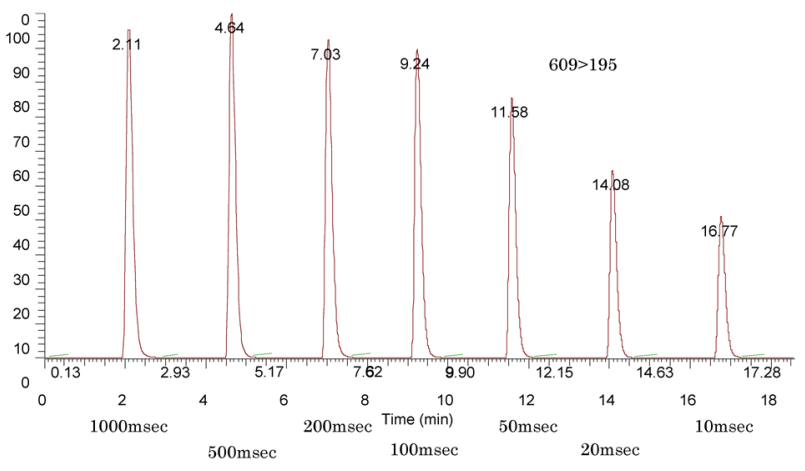

図3. Dwell timeの違いによるイオン強度の減少。高速イオン搬 送技術のない質量分析装置でのデータ. Dwell timeが $100 \mathrm{msec}$ より短くなるところから，徐々にイオン強度が下がっているこ とがわかる。
届かず，多少のタイムラグが生じる。このタイムラグの割合 はdwell timeが短くなればなるほど大きいものになり, 検出 されるイオン強度の減少となって現れる（図3）。この現象 が生じる大きな要因としてはq2（コリジョンセル）におけ るイオンの減速であるが，現在ではイオンの減速を防ぐため の搬送技術がいくつか開発されており, dwell timeを短くし てもイオン強度があまり減少しない装置も多く市販されてい る. 高速イオン搬送の技術例, その技術を用いて分析した事 例を図4-1, 図4-2に示した.

\section{3. 高速極性切り替え}

図2に示した分析メソッドで高速分析に寄与するパラメー

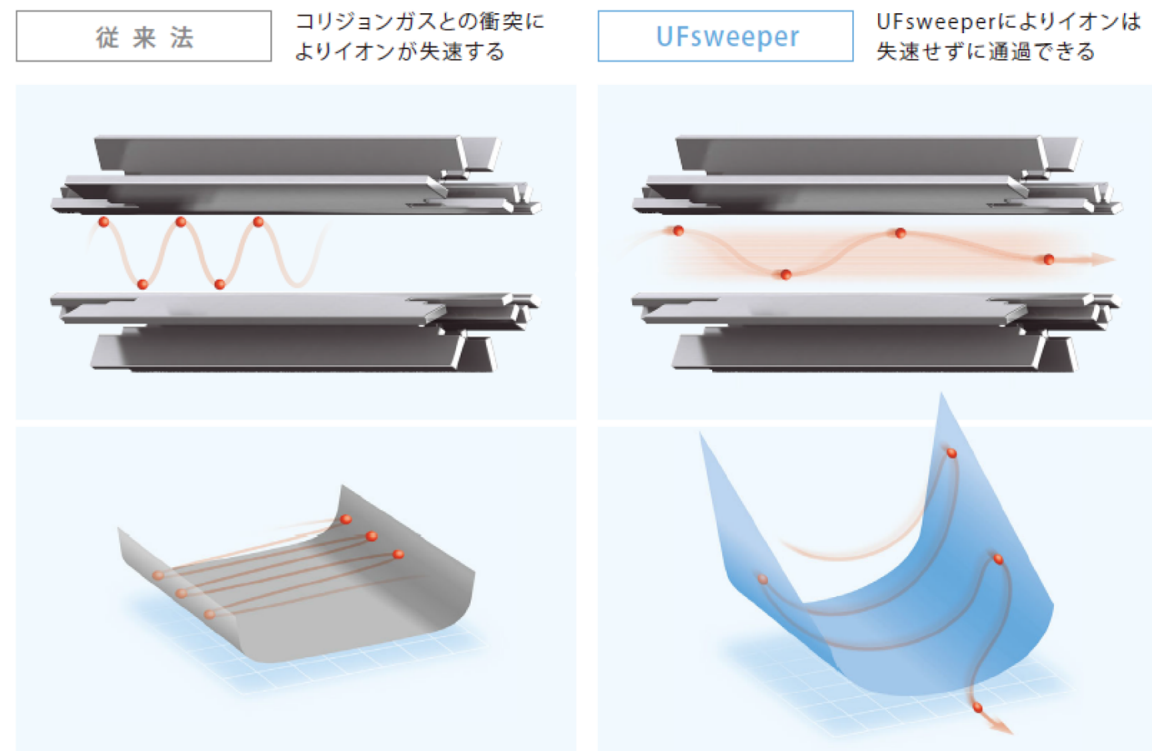

図4-1. イオン高速搬送技術．島津製作所LC-MS/MSで採用されているUFsweeper. コリジョンセルを必要最低限の長さに抑えつつ，高い CID 効率とイオンの高速搬送を実現した。疑似ポテンシャルを形成し，セルに大ってくるイオンを次々とスピーディにsweepingすることに より，高速測定においても信号強度の低下やクロストークの発生を防ぐ.

Alprazolam m/z 309>281 FWHM=3sec, Pause time 1msec,

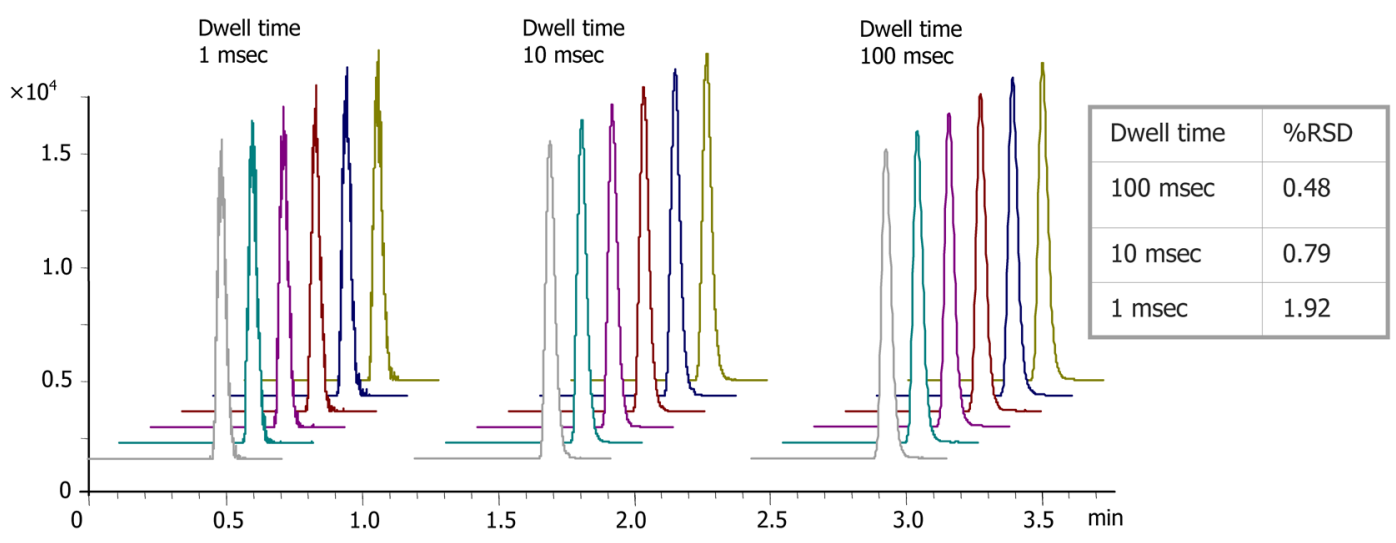

図4-2. イオン高速搬送技術を用いて分析した事例。島津製作所LCMS-8030でのdwell timeを変えたときの実分析データ。Dwell timeを $1 \mathrm{msec}$ まで短くしても, イオン強度の低下はほぼ見られない。 
タとして, 正負イオン化切り替え時間も重要である. 食品中 の残留農薬のスクリーニング分析においては，50３00成分 ほどをターゲットに分析をすることが多いが，そのすべてを 同じ極性（ポジティブイオン）で検出できるわけではなく, ポジティブモード，ネガティブモードでそれぞれ測定するこ とで，はじめて多成分を網羅することができる. 四重極型質 量分析計では, 2005年前後まで, 正負イオン化切り替え時 間の仕様が数 $100 \mathrm{msec}$ あ゙る装置が多く，ポジティブとネ ガティブの両方をひとつのメソッドで分析しょうとすると Loop timeが1秒をはるかに超えてしまうため, 二度に分け て分析する必要があった。この問題を解決するため, 最近開
発されている四重極型質量分析計では, 高電圧回路の技術革 新などにより, 切替え時間がわずか数 $\mathrm{msec}$ の超高速な正負 イオン化切り替えが実現されている。高速LC-MS/MS分析 において，正負イオン化切り替え時間は，ピーク形状に大き な影響を与えており,これが定量精度の優劣につながる（図 5,6 参照).

\section{4. 残留農薬の高速一斉分析例}

これまで述べてきた，高感度・高速イオン搬送・高速極 性切り替えの技術を使い, ミント, トマト, リンゴの抽出物 を，一般的な手法により前処理を行い，農薬の標準品を添加

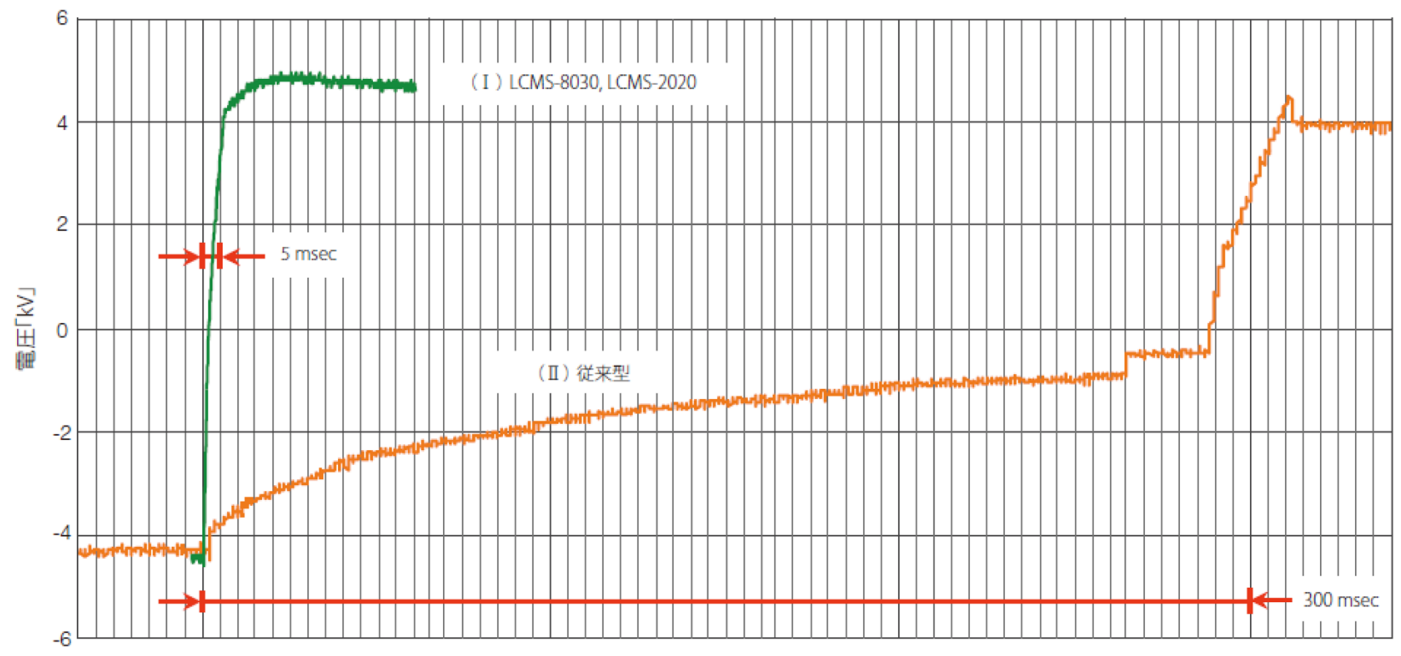

図5. 正負イオン化切り替え時の電圧モニター例.

Dwell 3, Pause 1, PN切替 15

Dwell 5, Pause 5, PN切替 20

Dwell 5, Pause 5, PN切替 500

Dwell 5, Pause 5, PN切替 700

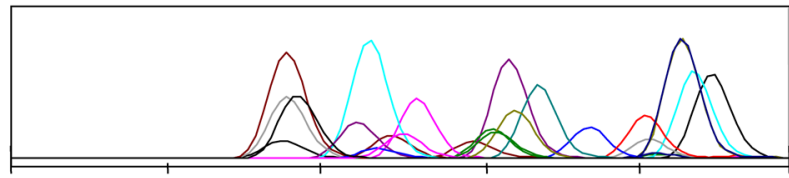

ex) Azimsulfuron

$\%$ RSD

$2.20 \%$

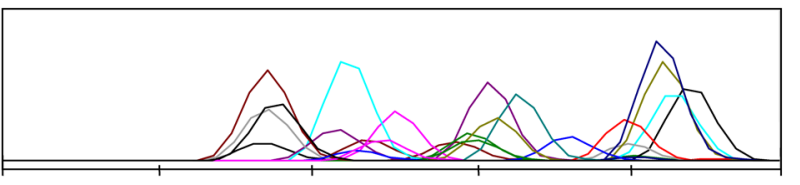

$\underline{4.62 \%}$

$36.87 \%$

$192.66 \%$

図6. 正負イオン化切り替え（PN）時間の差による分析データの違い。高速分析において正負イオン化切り替え時間が長いと，適切なクロ マトが得られない. 
したサンプルの分析を行った，高速一斉分析事例を図7-1-2 に，そのときの測定条件を表 2 に示した．短い分析時間の中 で1度の分析にてすべての化合物が検出でき, また, 面積值 再現性も $10 \mathrm{ppb}$ のレベルで良好なデータを得られている。

\section{5. おわり に}

UHPLC（超高速LC）が広く認知・普及され，LC-MS/ MSについてもそれに対応できる高速性能が必要になって
きた。定性分析に多用されている飛行時間型質量分析計や QTOF型質量分析計においても高速性能が備わってきてい る. 中でもトリプル四重極型質量分析計ではLCの高速性を 生かすために多くの技術が開発されており, 残留農薬分析で よく採用されている多チャンネルMRM分析では今後も多用 されていくだろう.

表2. 農薬646成分一斉分析の LC-MS/MS 測定条件

\begin{tabular}{|c|c|c|c|c|}
\hline \multicolumn{3}{|c|}{ Liquid chromatography } & \multicolumn{2}{|r|}{ Mass spectrometry } \\
\hline UHPLC & \multicolumn{2}{|c|}{ Nexera LC system } & LC-MS/MS & LCMS-8060 \\
\hline Analytical column & \multicolumn{2}{|c|}{ Restek Raptor biphenyl $(100 \times 2.1 \mathrm{~mm} .2 .7 \mu \mathrm{m})$} & Ionisation mode & Heated electrospray \\
\hline Column temperature & \multicolumn{2}{|l|}{$35^{\circ} \mathrm{C}$} & Polarity switching time & $5 \mathrm{msec}$ \\
\hline Flow rate & \multicolumn{2}{|l|}{$0.4 \mathrm{~mL} / \mathrm{min}$} & Pause time & $1 \mathrm{msec}$ \\
\hline Solvent A & \multicolumn{2}{|c|}{ Water $2 \mathrm{mM} \mathrm{NH}_{4}$ formate $0.002 \%$ formic acid } & Total MRM transitions & $1,929$ ( 1,824 positive; 105 negative $)$ \\
\hline Solvent B & \multicolumn{2}{|c|}{ Methanol $2 \mathrm{mM} \mathrm{NH}_{4}$ formate $0.002 \%$ formic acid } & MRM Dwell & $4 \mathrm{msec}$ (target ion); $1 \mathrm{msec}$ (reference ion) \\
\hline \multirow[t]{8}{*}{ Binary Gradient } & Time (min) & $\% \mathrm{~B}$ & Interface temperature & $350^{\circ} \mathrm{C}$ \\
\hline & 0 & 3 & Heating block & $300^{\circ} \mathrm{C}$ \\
\hline & 1 & 10 & Desolvation line & $150^{\circ} \mathrm{C}$ \\
\hline & 3 & 55 & Heating gas & $10 \mathrm{~L} / \mathrm{min}$ \\
\hline & 10.5 & 100 & Drying gas & $10 \mathrm{~L} / \mathrm{min}$ \\
\hline & 12 & 100 & Nebulising gas & $3 \mathrm{~L} / \mathrm{min}$ \\
\hline & 12.01 & 3 & & \\
\hline & 15 & Stop & & \\
\hline Injection volume & \multicolumn{2}{|c|}{$2 \mu \mathrm{L}$ sample (plus $40 \mu \mathrm{L}$ water) } & & \\
\hline
\end{tabular}

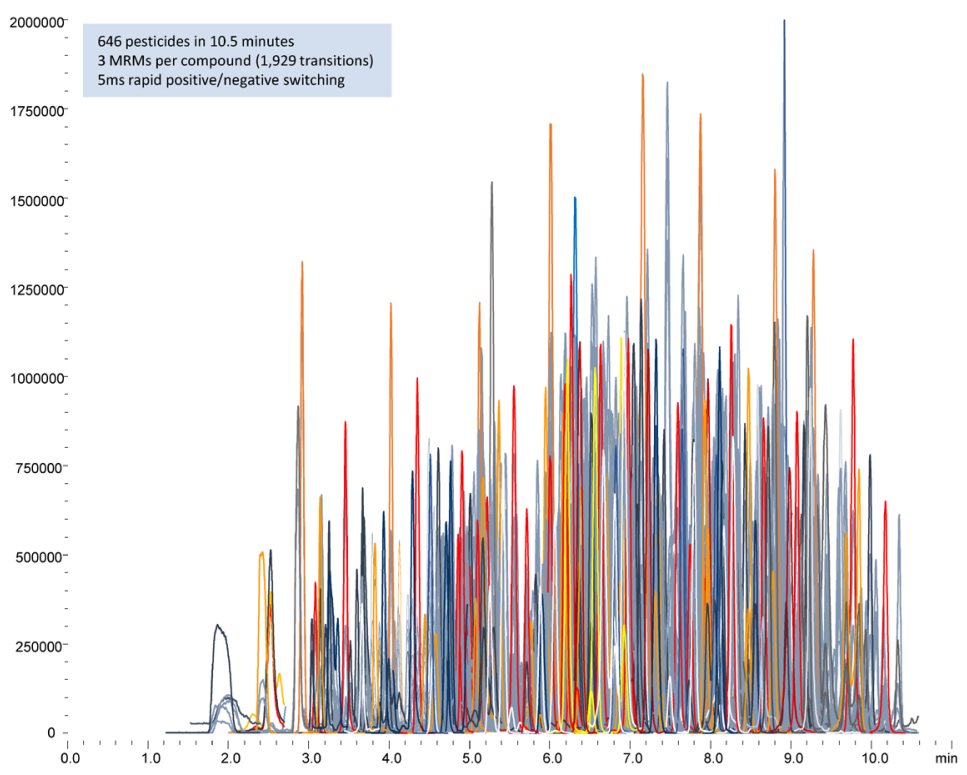

図7-1. 農薬646成分をミント抽出物に添加したときのLC-MS/MSクロマトグラム。島津製作所LCMS-8060にて分析．各化合物 $3 M R M$, ポジネガ切り替え $5 \mathrm{msec} .1$ 測定 15 分で分析が可能であった. 


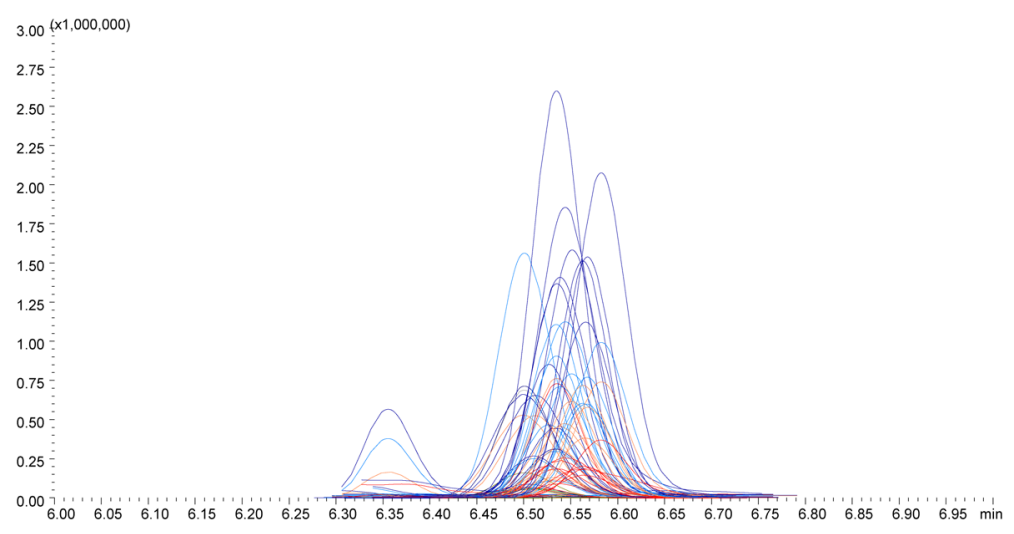

図7-2. 保持時間 6.45-6.6分には25成分がほぼ同じ保持時間で検出されているが, dwell timeを短く, 正負イオン化切り替え時間も短く設定 できているため, ピークに対するデータポイントを十分確保でき, データの再現性も良好であった.

\section{略 歴}

渡辺 淳（わたなべじゅん）

生年月日：1970年1月29日

最終学歴: 京都大学大学院農学研究科修了

主な職歴：2000年 4 月より現在まで LC/MSアプリケーショ ン関連業務を担当. 2010 年 7 月株式会社島津製作 所入社.

趣味：鉄道，テニス，渓流釣り 